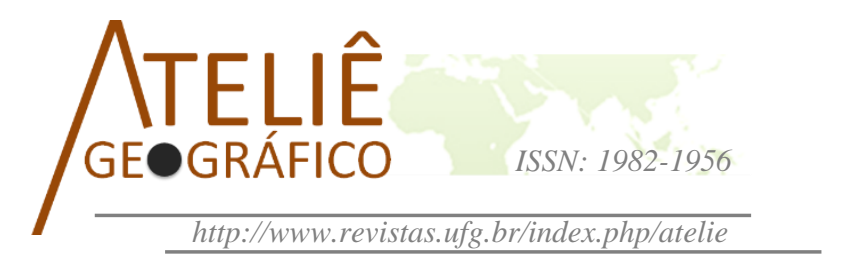

\title{
Do anime para o jogo: espaços evocativos de Os Cavaleiros do Zodíaco
}

\author{
From anime to game: evocative spaces of Saint Seiya. \\ Del anime para el juego: espacios evocadores de Los \\ Caballeros del Zodiaco
}

Washington Drummond da Silva

Universidade Federal do Rio de Janeiro

mr.slash2@yahoo.com.br

\begin{abstract}
Resumo
Esse artigo teve como objetivo analisar os espaços evocativos dos jogos Cavaleiros do Zodíaco: Alma dos Soldados e Os Cavaleiros do Zodíaco: Batalha do Santuário, e compreender o papel que a paisagem exerce em ambos. Como método realizou-se revisão bibliográfica dos estudos sobre os videogames, com destaque àqueles concernentes ao escopo da Geografia, assim como o contato mais íntimo com os espaços do anime, reassistindo as temporadas, e com os espaços evocativos dos jogos, jogando-os e observando considerações de outros jogadores. Verificou-se que os espaços evocativos dos jogos amplificam o senso de imersão dos jogadores no mundo ficcional de Os Cavaleiros do Zodíaco, assim como comunicam novas perspectivas da história e da espacialidade desse universo.

Palavras-chave: Representação; Videogames; Espaço do jogo; Espaços evocativos.
\end{abstract}

\begin{abstract}
The objective of this article was to analyze the evocative spaces of the Saint Seiya: Soldiers' Soul and Saint Seiya: Sanctuary Battle, and to understand the role played by the landscape in both of them. As a method, a bibliographical review of the studies on videogames was carried out, highlighting those concerning the scope of Geography, as well as the most intimate contact with the anime spaces, reassembling the seasons, and the evocative spaces of the games, playing them and observing other players' considerations. It has been found that the evocative spaces of the games amplify the sense of immersion of the players in the Saint Seiya fictional world, as well as the communicate new perspectives of the story and the spatiality of this universe.
\end{abstract}

Keywords: Representation; Videogames; Game space; Evocative spaces. 


\begin{abstract}
Resumen
Este artículo tuvo como objetivo analizar los espacios evocadores de los juegos Caballeros del Zodiaco: Alma de los Soldados y Los Caballeros del Zodiaco: Batalla del Santuario, para comprender el papel que el paisaje ejerce en ambos. Como método, se realizó una revisión bibliográfica de los estudios sobre los videojuegos, con destaque a aquellos concernientes al alcance de la Geografía, así como el contacto más íntimo con los espacios del anime, reasistiendo las temporadas. En relación a los espacios evocadores de los juegos, se buscó jugarlos e incluso, observar las consideraciones de otros jugadores. Se verificó que los espacios evocadores de los juegos amplían el sentido de inmersión de los jugadores en el mundo ficcional de Los Caballeros del Zodiaco, así como comunican nuevas perspectivas de la historia y de la espacialidad de ese universo.
\end{abstract}

Palabras clave: Representación. Videojuegos. Espacio del juego. Espacios evocadores.

\title{
Introdução
}

Os videogames, ou jogos eletrônicos em tradução literal, têm se firmado cada vez mais na cultura ocidental contemporânea. Esses dispositivos recreativos passaram a ser socialmente consumidos em meados dos anos 80, quando seus primeiros passos foram dados no mercado de $\operatorname{arcades}^{l}$. Desde então, os jogos eletrônicos sofreram diversas mudanças (e continuam sofrendo desde a sua apresentação visual até os seus modos de jogar) o que só ampliou o seu enraizamento nos hábitos coletivos.

Segundo o teórico linguista de estudos voltados aos videogames, Aeserth (2000), esses jogos, no início do século XXI, já apresentavam o crescimento mais rápido dentre os setores culturais do mundo industrializado. O site Superdata ${ }^{2}$ aponta que, desde 2007, os faturamentos anuais da indústria dos videogames superam os ganhos da indústria cinematográfica. $\mathrm{O}$ mesmo site ainda afirma que uma a cada três pessoas no planeta, jogam, ao menos, games gratuitos em PCs (computadores) ou plataformas móveis (celulares).

Sem dúvida, os jogos têm implicado revoluções no nosso comportamento social (para alguns indivíduos eles criam obrigações sociais que impactam sobre os relacionamentos pessoais desses jogadores) e despontam como importantes ferramentas no desenvolvimento de faculdades humanas, como: a melhoria do raciocínio, da coordenação motora, do funcionamento cerebral, das habilidades mentais e da aprendizagem (Vandellós, 2010; Colom, 2012). O futuro parece pertencer àqueles que conseguem entender, criar e interagir com esses desafios digitais repletos de fantasia (McGogigal, 2012).

Mesmo diante de tamanha significância, desde que iniciei os estudos sobre esse veículo de comunicação e entretenimento, em 2011, notei que as décadas anteriores,

\footnotetext{
${ }^{1}$ Grandes máquinas revestidas por madeira e desenhos que propagandeiam seu jogo. Possui internamente televisores e o sistema de jogo e na face externa as alavancas, botões, volantes, entre outras opções de controle. No Brasil era popularmente chamado de fliperama.

2 <https://www.superdataresearch.com/market-data/market-brief-year-in-review/> acessado em 14/02/2018
} 
(sobretudo 80 e 90), apresentavam um enorme vazio de discussão sobre o tema. O que me permitiu afirmar, portanto, que até aquele momento, os videogames eram negligenciados enquanto objetos de estudo, produzindo um cenário no qual trabalhos com essa temática eram escassos.

O panorama atual já não nos permite mais fazer tal afirmação. A partir do final dos anos 90 e início dos anos 2000, começaram a ganhar vida, alguns ensaios sobre os videogames, suas potencialidades, limitações e impactos na vida social (e pessoal) dos usuários. A datar desse momento, alguns ramos da ciência, das artes e da filosofia se debruçaram com maior afinco pelo universo digital dos jogos eletrônicos. Se hoje ainda não se pode afirmar tratar-se de um tema de intenso debate acadêmico, por outro lado, também não possível negar o fato de que nunca o discutimos tanto, inclusive com a emergência (e conflitos ${ }^{3}$ ) de campos (que se almejam enquanto) próprios de estudo, com perspectivas particulares (Gomes, 2009).

Essas abordagens específicas podem ser apreendidas pelo debate entre os defensores do campo da Ludologia e os da Narratologia. Os termos nascem na década de 90 com a publicação das obras Cibertext: perspectives on Ergotic Literature (Aarseth, 1997) e Hamlet on the Holodeck: The Future of Narrative in Cyberspace (Murray, 1998).

A perspectiva ludológica propõe que os estudos contemplem um olhar do jogo pelo jogo, ou seja, focando em sua mecânica, regras, estrutura de funcionamento e afins, o que vai convergir para a noção de jogabilidade. Já a perspectiva narratológica, enaltece o potencial narrativo do jogo e a sua capacidade de contar histórias, muitas vezes em analogia direta com a linguagem cinematográfica (Jenkins, 2004).

Lindley (2003) argumenta que a estrutura narrativa mais usada nos jogos é a estrutura em três atos de reparação tomada emprestada do cinema. Ela consiste no estabelecimento de um conflito inicial (primeiro ato), nas implicações desse conflito (segundo) e, finalmente, na sua resolução (terceiro). Como exemplos temos os clássicos jogos da franquia Super Mario da Nintendo onde o primeiro ato geralmente envolve o rapto da princesa, o segundo ato contempla o jogo em si e, ao final da campanha, o resgate da princesa simboliza o terceiro ato.

Para a Geografia, entretanto, as duas abordagens; e mais aquela voltada aos jogos de simulação (Drummond, 2014); apresentam enorme potencial (figura 01), haja visto que, para qualquer jogo eletrônico, há um imperativo básico que é a existência de uma estrutura espacial sobre a qual a mecânica ou narrativa do jogo se manifestam (Aaserth, 2000), ou seja, um espaço onde, efetivamente, o jogo acontece, se desenrola. Esse espaço, contudo, não exerce apenas papel situacional ou de substrato, mas vai além, condicionando as ações do jogador (Aarseth, 2000 e Mussa, 2011) e comunicando ao usuário uma série de informações (Jenkins, 2004 e Drummond, 2014).

\footnotetext{
${ }^{3}$ Gomes (2009) dedica seu artigo a recontextualizar as rixas teóricas entre ludologistas e narratologistas.
} 


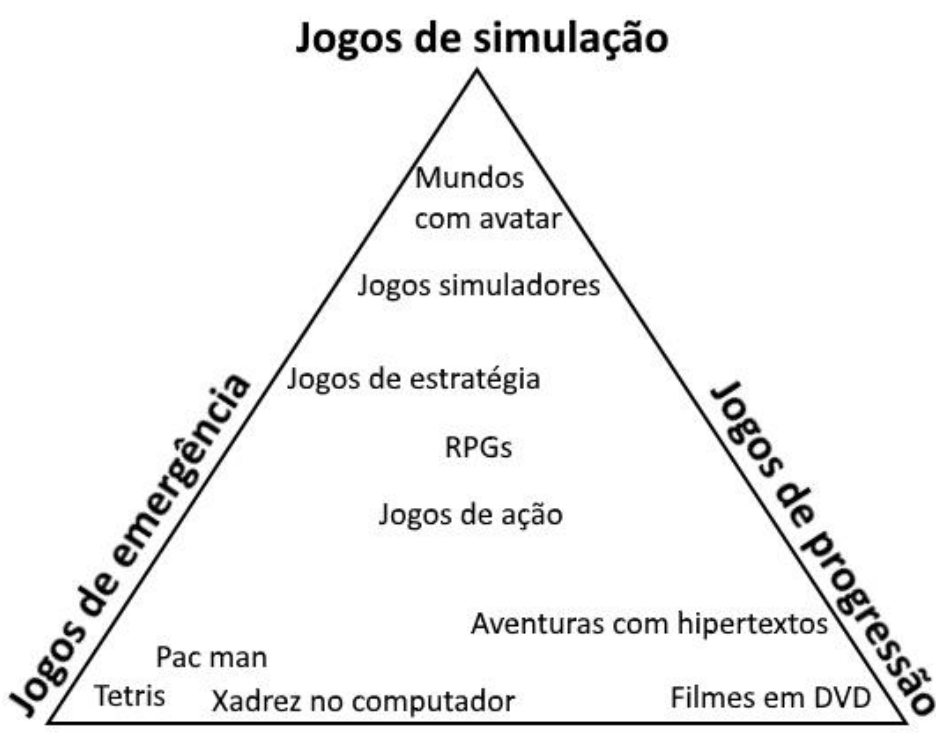

Figura 01: Taxonomia dos videogames.

Fonte: Adaptado de Lindley (2003).

Em outras palavras, nenhum videogame se realiza sem a representação do espaço. Em minha dissertação de mestrado (Drummond, 2014), tentei demonstrar os elementos básicos contidos na representação espacial feita pelos videogames. Observei quatro elementos (quadro 01) que atuam de forma combinada, mas com preponderância alternáveis de acordo com cada jogo.

Quadro 01: Quadro de componentes da representação espacial

\begin{tabular}{|l|c|}
\hline \multirow{4}{*}{$\begin{array}{l}\text { Componentes da representação } \\
\text { espacial feita pelos videogames. }\end{array}$} & Interatividade \\
\cline { 2 - 2 } & Territorialidade digital \\
\cline { 2 - 2 } & Imersão \\
\cline { 2 - 2 } & Navegabilidade espacial \\
\hline
\end{tabular}

Fonte: Drummond (2014).

Nesse ponto, um primeiro dilema surge: os videogames realizam uma representação do espaço ou a apresentação de um espaço? Se concordamos com a segunda opção, concluiremos que não há representação, mas a apresentação de um espaço próprio, autônomo. Esse debate nos leva ao questionamento se os jogos reproduzem a "realidade" (ainda que de forma ficcional) ou se são, de fato, uma outra realidade. 
Inclino-me a adotar uma posição ponderada. Os jogos eletrônicos não são a representação fiel da realidade, pois, entre outras coisas, demandam reduzir-se à caricaturas pela necessidade da implementação dos parâmetros e regras de um jogo. Como exemplo: posso me recuperar de tiros comendo plantas em Resident Evil 5 ou me teletransportar de um ponto a outro do cenário em do jogo em LOTRO (Lord of The Rings On Line).

Em sintonia com a linha de raciocínio exposta acima, Aaserth (2000) admite que os videogames são "alegorias do espaço: eles fingem retratar o espaço de maneiras cada vez mais realistas, mas dependem do desvio da realidade para tornar a ilusão reprodutivel" (Aaserth, 2000, p. 169, traduzido pelo autor ${ }^{4}$ ).

Em contrapartida, não é concebível que os videogames sejam um espaço completamente autônomo, pois não há como negar que tomam como referência objetos, processos e fenômenos do mundo físico e social. Basta observar que as lacunas deixadas pelos espaços e narrativas desses jogos são preenchidas pela nossas expectativas, familiaridades e vivências anteriores ao mundo do jogo.

Exemplificando o parágrafo anterior, compreendemos, sem o menor problema, que um personagem em The Sims 2, recuse-se a sair de casa, em meio a uma possível depressão, após terminar um casamento duradouro, ainda que isso pareça extremamente clichê. Aliás, talvez por ser clichê é que esteja tão assentado em nossas mentes e, consequentemente, reproduzido nos jogos.

Até mesmo quando temos um jogo que imagina-se na qualidade de absoluta ficção, as referências mundanas se fazem presentes, verifica-se isso em Spore (um simulador de evolução da vida de espécies animais fictícias). Nele, ignorando a seleção natural e a especiação, são os jogadores que criam as espécies e que escolhem as suas mutações, o que é inteiramente ficcional. Em contrapartida, qualquer criatura viva da galáxia (via láctea ${ }^{5}$ ) precisa passar, obrigatoriamente, por uma evolução que é linear, desde organismos marítimos simples, até seres terrenos complexos e urbanos, uma clara referência à evolução humana.

Em suma, os videogames compreendem uma realidade própria, mas que toma como referencia o real tangível. Não há a pretensão e nem a intenção de prolongar, nesse artigo, tal assunto que demandaria uma discussão com enorme profundidade e complexidade, talvez paralisante. Porém, para que seja possível avançar o objetivo aqui almejado, será adotado o termo "espaço do jogo" (o cenário onde ocorrem as ações) para se referir à geografia particular de cada videogame.

Sobre esse aspecto, é importante citar o trabalho de Ash e Gallecher (2011) intitulado "As geografias culturais dos videogames ${ }^{6 ",}$ no qual os autores apontam três

\footnotetext{
4 "Computer games, finally, are allegories of space: they pretend to portray space in ever more realistic ways, but rely on their deviation from reality in order to make the illusion playable."

${ }^{5} \mathrm{O}$ próprio nome da galáxia já é uma evidente referência mundana. Vale ainda ressaltar que o sistema solar e o planeta Terra possuem uma versão presente no jogo.

6 "The cultural geographies of videogame" (Ash e Gallecher, 2011)
} 
vertentes de estudos dos jogos eletrônicos pela Geografia. Uma dessas, "a geografia nos videogames $^{7 "}$, corresponde à Geografia contida no interior dos próprios jogos, no universo das suas re(a)presentações (Gomes, 2008). É onde o presente estudo se insere.

Adentrando a vertente da geografia nos videogames, em recente estudo (Drummond, 2016) sistematizei sete possibilidades de abordagens (figura 03) e focarei nesse trabalho em uma delas, a que corresponde aos papéis desempenhados pela paisagem nos jogos eletrônicos. Para isso, tomarei emprestado (para maior especificidade) a perspectiva dos "espaços evocativos", elaborada por Jenkins (2000) em seus artigo "Desing de jogos como arquitetura narrativa ${ }^{8 "}$. Nele o autor aborda a correlação entre os videogames e outras mídias.

Jenkins (2004) levanta a ideia de "histórias ambientais" utilizando como exemplo os parques da Disney. Com base nessa concepção, os elementos espaciais da história ficcional são infundidos na paisagem (espaço físico) dos parques visando inserir (ou aumentar a sensação de imersão) o visitante nesse mundo. Esse processo corrobora as expectativas semióticas dos usuários, ou seja, as suas fantasias pré-existentes. Atestase, com isso, um papel específico conferido às paisagens, que são criadas para transmitir informação.

Quadro 2: Eixos de abordagem geográfica nos videogames.

\begin{tabular}{|c|c|}
\hline \multirow{4}{*}{$\begin{array}{c}\text { Possíveis eixos de abordagem da } \\
\text { Geografia nos videogames. }\end{array}$} & $\begin{array}{c}\text { A importância da espacialidade e dinâmica } \\
\text { espacial na jogabilidade. }\end{array}$ \\
\cline { 2 - 2 } & Forma como os lugares são representados. \\
\cline { 2 - 2 } & $\begin{array}{c}\text { A vivência dos lugares virtuais ou no } \\
\text { virtual. }\end{array}$ \\
\cline { 2 - 2 } & $\begin{array}{c}\text { Produção e consumo de um imaginário } \\
\text { geográfico. }\end{array}$ \\
\cline { 2 - 2 } & Representações sociais. \\
\cline { 2 - 2 } & Conceitos e fenômenos representados. \\
\cline { 2 - 2 } & $\begin{array}{c}\text { Papeis desempenhados pela paisagem nos } \\
\text { jogos. }\end{array}$ \\
\hline
\end{tabular}

Fonte: Drummond, 2016.

O mesmo processo de ambientação, de forma ainda mais ampla, ocorre nos videogames, nesse sentido, penso que o termo "ambiência" seja conceitualmente mais adequado, como expus em minha dissertação de mestrado (Drummond, 2014). A ambiência visa dar estrutura e significado à experiência do visitante no espaço do jogo e o faz a partir de elementos da paisagem, tais como texturas, formas, cores, composições, sons, iluminação, enquadramento, assim como a interação com os objetos e os aspectos

\footnotetext{
7 "The Geographies in Videogames: Representations and Politics" (Ash e Gallecher, 2011)

8 "Game Design as Narrative Architecture" (Jenkins, 2004)
} 
da jobabilidade (jostique, instrumentos musicais, corpo do jogador, movimentação do avatar, física do jogo, etc.).

Trata-se de uma infinidade de signos que tem a missão de imergir o jogador no espaço do jogo, e para isso, dialoga com as expectativas semióticas espaciais do mesmo. Quanto maior for a confirmação da expectativa, maior é a sua imersão no jogo. Os jogadores, em um pântano equatorial, esperam encontrar jacarés. A presença de baleias, pinguins, ursos polares e neve, causaria estranheza. O som de uma bomba explodindo no chão ou de pássaros cantando em uma floresta, funcionam de mesmo modo, compondo a paisagem sonora.

A concepção de ambiência e suas expectativas semióticas no espaço do jogo, se assemelham ao conceito de cenário desenvolvido pelo geógrafo Gomes (2008). O autor argumenta que a dimensão física dos espaços propõe as ações, desse modo, ele sugere reconectar os arranjos espaciais aos comportamentos socais.

Para Jenkins, a ambiência cria condições prévias para uma experiência narrativa imersiva a partir de quatro maneiras: os espaços evocativos, os espaços que promovem histórias, espaço das narrativas incorporadas e espaço das narrativas emergentes.

Os "espaços que promovem histórias" são mundos básicos em que a narrativa ocorre de forma bem linear, geralmente em três atos: apresenta-se o conflito e objetivo ao início da campanha ( $1^{\circ}$ ato), posteriormente o jogador se defronta com os obstáculos ( $2^{\circ}$ ato) e, finalmente, temos a resolução do conflito ( $3^{\circ}$ ato). Temos como exemplo o famoso jogo Super Mário World.

Nos "espaços das narrativas incorporadas ${ }^{10 "}$, diversos eventos são inseridos paulatinamente na medida que exploramos o espaço do jogo e, com isso, o enredo vai se revelando. Nessa estrutura espacial, a narrativa segue o modelo clássico das histórias de detetives, onde a cada área explorada e objetos investigados, novas informações são descobertas e incorporadas à trama. As peças dos quebra-cabeças são unidas apenas no desfecho da história, resolvendo os enigmas ou apresentando reviravoltas. Um bom exemplar é o atual Resident Evil 7.

Os "espaços de narrativas emergentes ${ }^{11 "}$ são aqueles sem qualquer pré estruturação ou pré programação, no qual a narrativa toma toda a sua forma a partir das escolhas feitas pelo jogador. Neles os jogadores podem definir os seus próprios objetivos e escrever suas histórias pessoais dentro do espaço do jogo. Os jogos SimCity 4 e SimCity 2013 apresentam essa dinâmica (Drummond, 2014).

Os "espaços evocativos ${ }^{12 "}$, por fim, são aqueles que não contam histórias autônomas, eles abordam histórias já conhecidas. Esses jogos se baseiam em narrativas ou gêneros já existentes, provenientes de outros veículos (filme, livro, seriado, anime,

\footnotetext{
${ }^{9}$ Enacting stories.

${ }^{10}$ Embedded narratives.

${ }^{11}$ Emergent narratives.

${ }^{12}$ Evocative spaces. Todos traduzidos pelo autor.
} 
quadrinho, cartuns, etc.), e evocam a atmosfera da história original, adaptando-a para o universo do videogame.

Grande parte dos jogadores já conhecem a história original antes mesmo de acessar o jogo, então munidos de um mapa mental composto pelos personagens, espaços, situações e objetos do ambiente ficcional que ele espera encontrar. Nesse sentido, o grande diferencial dos videogames, frente aos outros meios no qual essa história transmidiática também pode ser adaptada, é fornecer um ambiente imersivo onde os jogares possam explorar de forma ativa (navegar, interagir, percorrer e vivenciar). Tratase de uma experiência única que as outras mídias não conseguem oferecer.

Jenkins (2004) comenta que essas histórias transmidiáticas podem produzir dois efeitos. De um lado, cada obra pode participar na construção de uma narrativa mais ampla ao comunicar uma nova perspectiva da história, através de alteração ou adição de alguns detalhes. Do outro lado, pode melhorar o nosso senso de imersão dentro daquele mundo familiar. Sejam quais forem os efeitos produzidos (apenas um dos dois efeitos ou ambos), o autor admite que elas enriquecem e expandem a nossa experiência com os universos das obras.

Baseado na contribuição de Jenkins (2004), esse artigo objetiva analisar os espaços evocativos dos jogos Cavaleiros do Zodíaco: Alma dos Soldados (PC) e Os Cavaleiros do Zodíaco: Batalha do Santuário $\left(\mathrm{PS}^{13}{ }^{13}\right.$, e compreender o papel que a paisagem exerce nesses jogos.

A metodologia consistiu basicamente no acesso à bibliografia específica que envolve os estudos sobre os videogames, com destaque àqueles concernentes ao escopo da Geografia; dentre eles, a obra de Jenkins (2004), da qual tomou-se emprestado a noção dos "espaços evocativos" enquanto ferramenta analítica.

Outra etapa operacional foi dedicada ao contato mais direto com os cenários no anime e com os seus espaços evocativos correspondentes nos jogos. Em ambos os casos, algumas imagens (recortes estáticos dentro de um plano sequencia maior) representativas foram cuidadosamente selecionadas e utilizadas nesse artigo. Para tal feito, as temporadas do anime foram (re)assistidas e os videogames foram jogados. Mesmo se tratando de dois distintos veículos artísticos, com linguagens próprias, buscou-se uma linha interpretativa convergente.

A série Saint Seiya, conhecida no Brasil como "Os Cavaleiros do Zodíaco", foi publicada originalmente em 1985, no formato de mangá, na revista japonesa Weekly Shōnen Jump. Um ano depois ganhou uma adaptação em anime para ser exibida em televisão como seriado e em VHS como filmes.

$\mathrm{O}$ anime, produto mais famoso da série (com algumas diferenças no enredo comparadas ao mangá), foi inspirado em Astronomia e nas mitologias grega e nórdica. Possui, ao todo, 5 temporadas ou sagas (Santuário, Asgard, Poseidon, Hades e Alma de

13 O termo "PC" refere aos computadores de mesa e o "PS3" ao console Playstation 3. 
Ouro), sendo a temporada inicial (Santuário) a mais famosa e o enredo central do segundo jogo aqui analisado: Os Cavaleiros do Zodíaco Batalha do Santuário (PS3).

Os espaços do anime que abrigam as tramas de cada temporada são: o santuário da Grécia (Santuário e Hades), inspirado na arquitetura clássica greco-romana e na ideia de superioridade associada a pontos mais elevados do terreno ${ }^{14}$ (figura 02); as terras geladas de Asgard no norte europeu, reino dos deuses nórdicos (Asgard e Alma de Ouro), o Inferno (Hades), os Campos elísios (Hades) e ainda o templo submarino de Poseidon (Poseidon).

Os dois jogos possuem mecânicas um pouco diferentes, embora ambos sejam jogos de luta. O primeiro (Os Cavaleiros do Zodíaco: Alma dos Soldados- AS) foca exclusivamente em combates de um personagem contra o outro, sem trajetos à percorrer. Ele também possui um ponto de vista focal no qual nenhum dos lutadores gozam de uma posição de destaque, mas alternam, de acordo com a dinâmica na luta, as suas posições (figura 02).

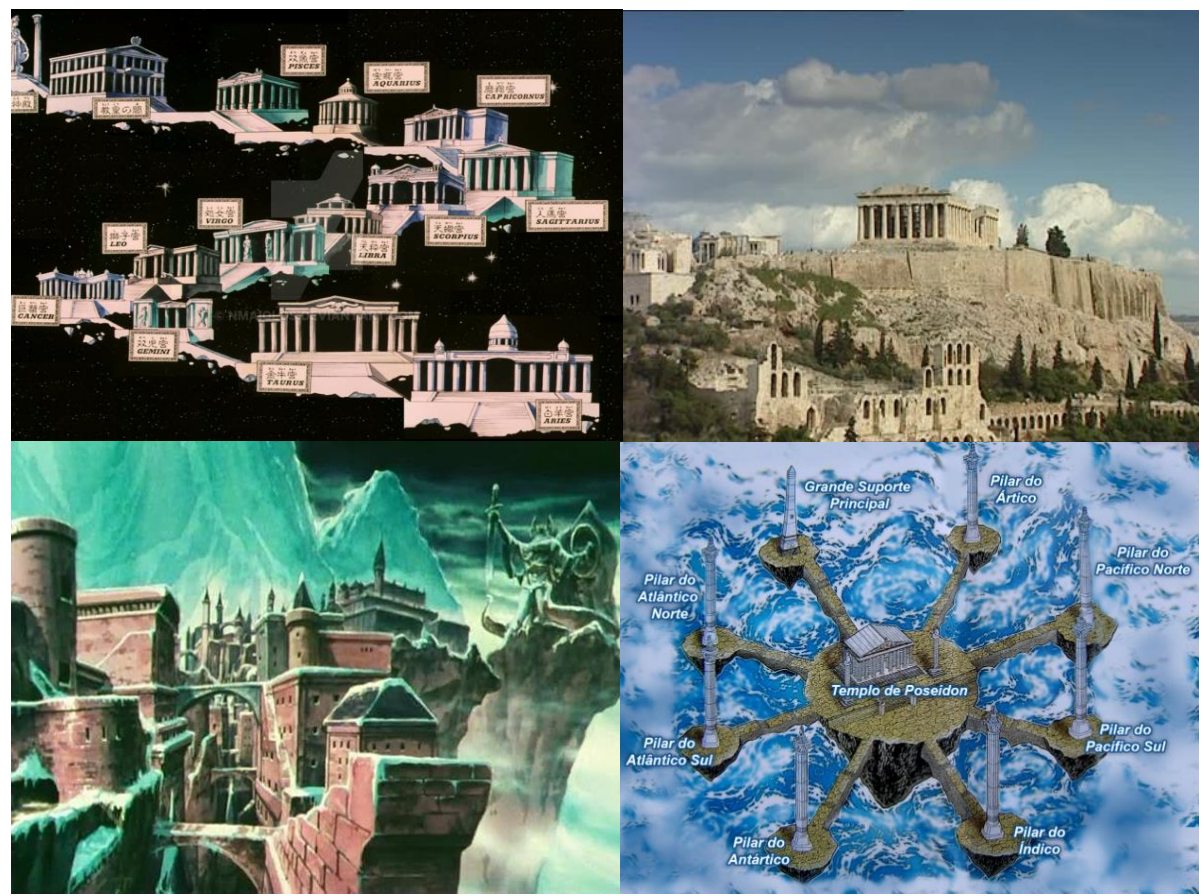

Figura 02: Espaços do anime. Da esquerda para direita acima: Santuário de Atena em $O \vec{s}$ Cavaleiros do Zodíaco e o Panteão grego (arquitetura clássica greco-romana).

Abaixo: Asgard e templo marino de Poseidon.

Fonte: Elaborado pelo autor (2018).

${ }^{14}$ Os cavaleiros de bronze têm a necessidade de subir uma travessia com 12 casas zodiacais guardadas, cada uma, por um cavaleiro de ouro inimigo até chegar à sala do grande mestre e da deusa Athena. 
Já o segundo (Os Cavaleiros do Zodíaco: Batalha do Santuário- BS) é necessário se deslocar pelo espaço do jogo (o santuário de Atena) e enfrentar inimigos mais fracos para chegar até aos pontos principais de luta (as doze casas zodiacais). Tanto no percurso, quanto nas lutas principais, o ponto de vista focal centraliza o personagem avatar, aquele que está sendo controlado pelo jogador (figura 05).

A par dos devidos esclarecimentos, focar-se-á, daqui em diante, nos espaços e paisagens dos jogos selecionados.

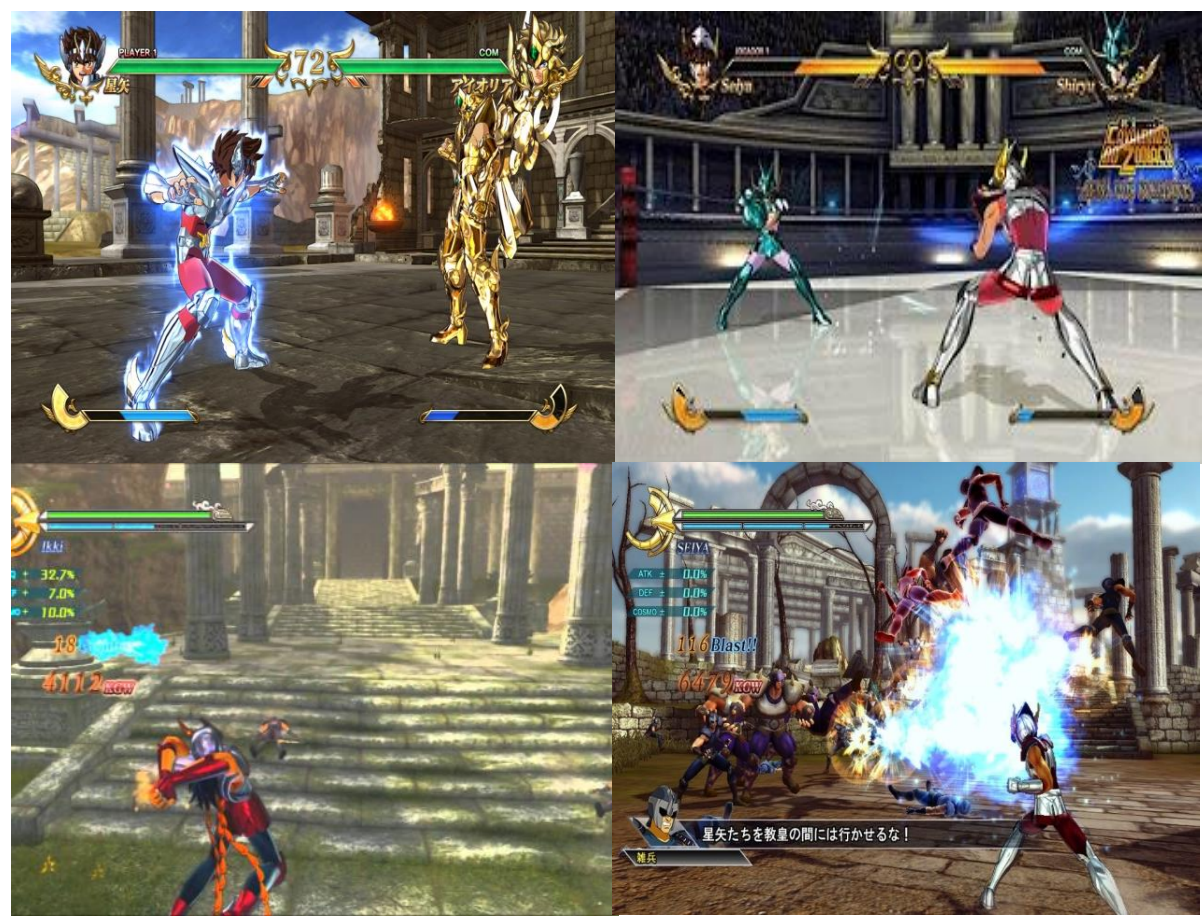

Figura 05: Espaços dos jogos. Acima: Os Cavaleiros do Zodíaco: Alma dos Soldados. Abaixo: Os Cavaleiros do Zodíaco: Batalha do Santuário.

Fonte: Elaborado pelo autor (2018).

\section{Os Cavaleiros do Zodíaco: Alma dos Soldados}

Em Os Cavaleiros do Zodíaco: Alma dos Soldados, as cinco sagas do anime são contempladas, portanto, encontramos cenários que estão presentes em os todos os capítulos da história original. Todavia, alguns cenários são, naturalmente, mais caprichados que outros, de modo a apresentar mais elementos icônicos, que são imediatamente reconhecidos pelos jogadores na composição da paisagem.

Buscando abranger o máximo de cenários possíveis da obra, contemplou-se em cada figura uma temporada, com exceção da figura 08 que abarca duas temporadas 
(Asgard e Alma de Ouro) ao mesmo tempo, pois ambas se desenrolam no mesmo lugar fictício: Asgard. Nessa trilha, foi vital explorar os elementos espaciais icônicos de cada saga, aqueles que concentram grande representatividade no interior da obra.

$\mathrm{Na}$ figura 06 vemos o coliseu onde ocorre a guerra galáctica, um torneio entre os cavaleiros de bronze. Observa-se que o jogo reproduziu com grande detalhamento o espaço interno, captando elementos de maior destaque na paisagem. Notamos que o ringue está limitado pelas correntes e contêm os desenhos triangulares negros grafados no piso, tal como no anime. Ao fundo, a plateia que lota o ginásio se faz presente, assim como a valiosíssima armadura dourada de sagitário (o prêmio para o lutador vencedor) que está destacada na paisagem em razão da altura elevada e por concentrar um enorme feixe de luz constante em sua direção.

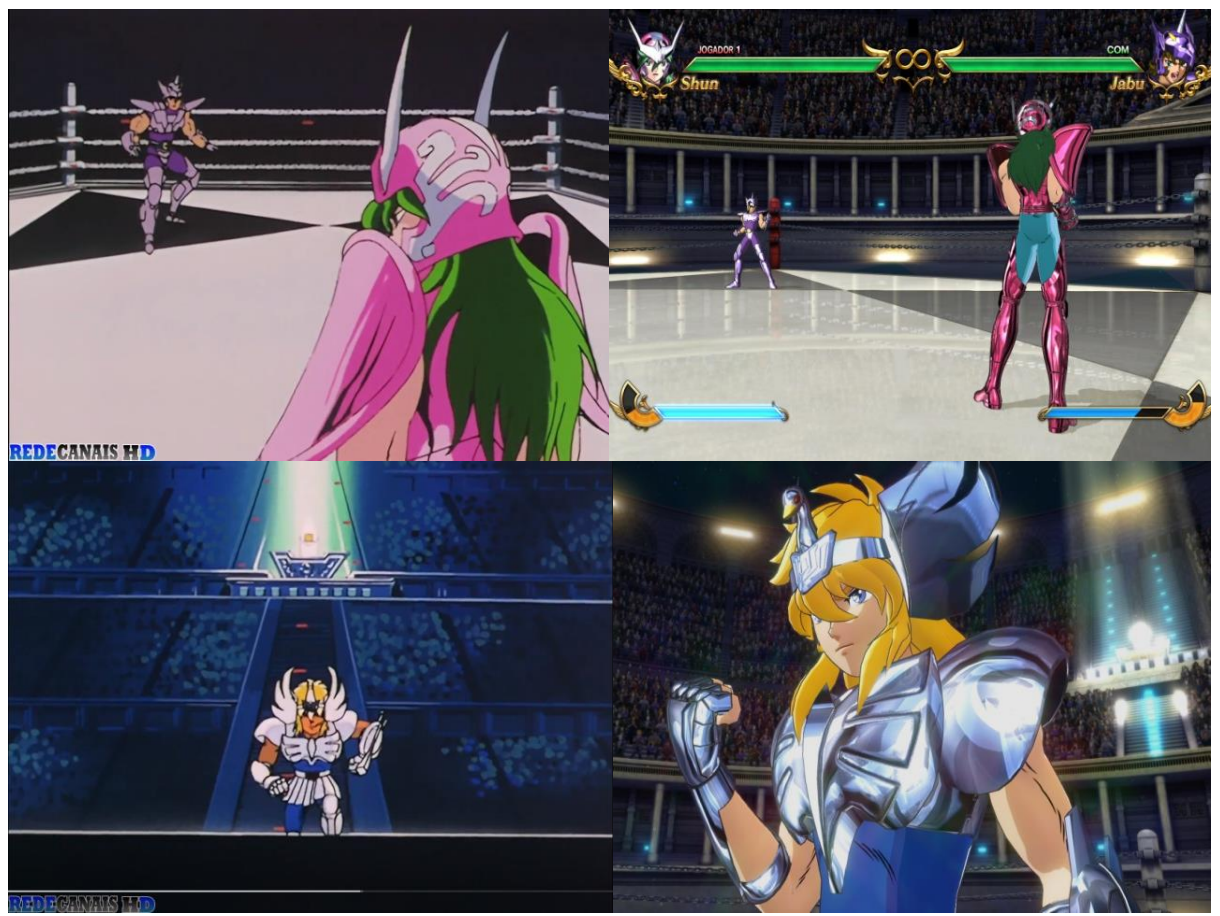

Figura 06: À esquerda o coliseu no anime e à direita o coliseu no espaço do jogo Os Cavaleiros do Zodíaco: Alma dos Soldados.

Fonte: Elaborado pelo autor (2018).

No arco do santuário, foram selecionadas as casas zodiacais de Virgem e de Sagitário para a demonstração. Na casa de Virgem, tal como o anime, o jogo representa a flor de lótus (local de meditação do cavaleiro de Virgem) ao fundo do cenário, separada do salão de luta por uma pequena escada de degraus largos. O piso produzido por placas quadrangulares típico do anime também está presente no espaço do jogo. 
Já na casa zodiacal de Sagitário, há, em uma das paredes, um testamento talhado à mão. O recado foi deixado pelo falecido cavaleiro dourado dessa constelação, Aiolos. Em companhia aos testamentos, encontra-se uma flecha dourada da armadura do próprio cavaleiro (de Sagitário). O jogo reproduz fielmente todos esses espólios. A sensação que passa é que o seu personagem escolhido para a aventura está efetivamente dentro da casa de Sagitário.

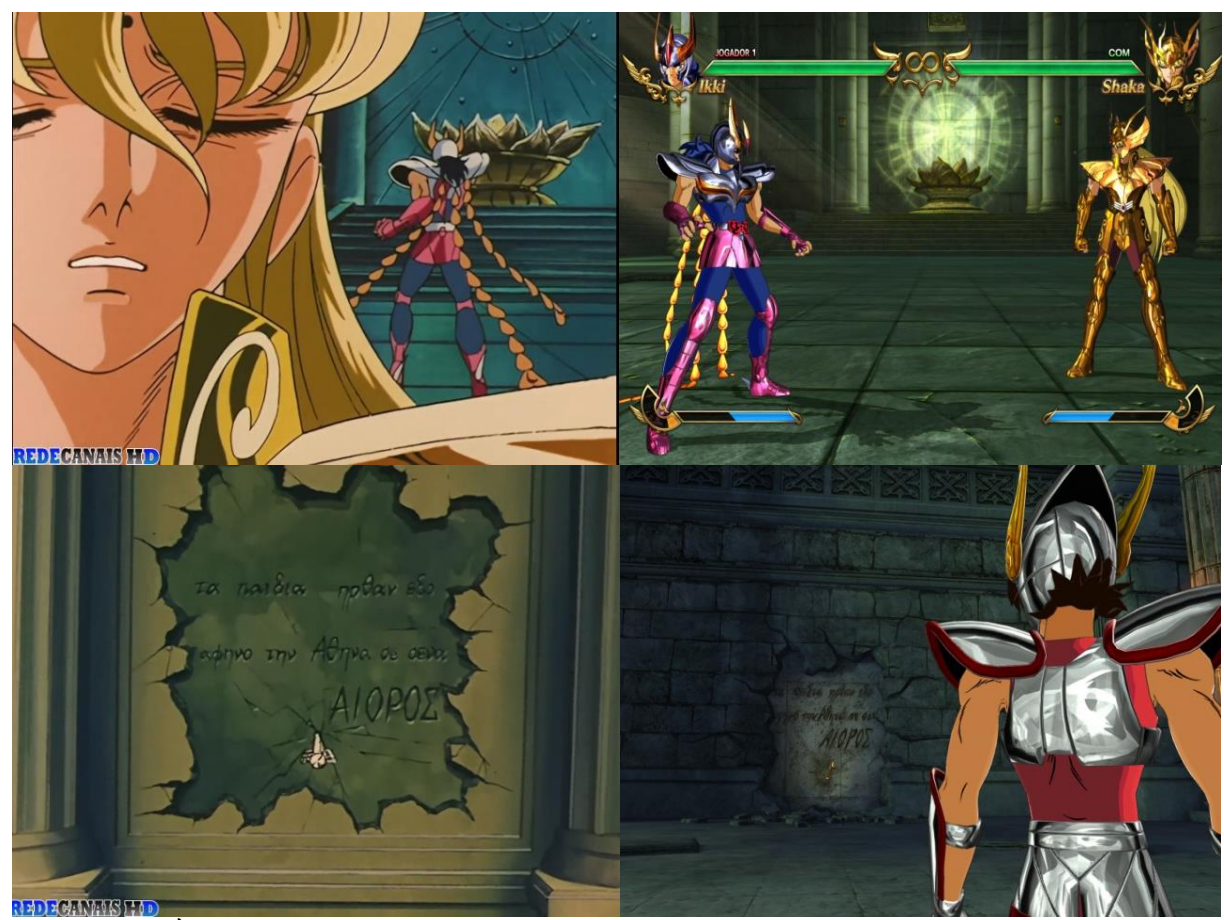

Figura 07: À esquerda as casas do santuário no anime e, à direita, no espaço do jogo $O s$ Cavaleiros do Zodíaco: Alma dos Soldados.

Fonte: Elaborado pelo autor (2018).

Na saga de Asgard, a caverna vulcânica e o palácio de Valhalla foram contemplados. A caverna vulcânica é composta por um lago de lava e apresenta pequenas protuberâncias rochosas, com diversos tamanhos, por onde se desenvolve o confronto entre os cavaleiros de Merak e de Cisne. Essas características foram transpostas para o espaço do jogo também. 


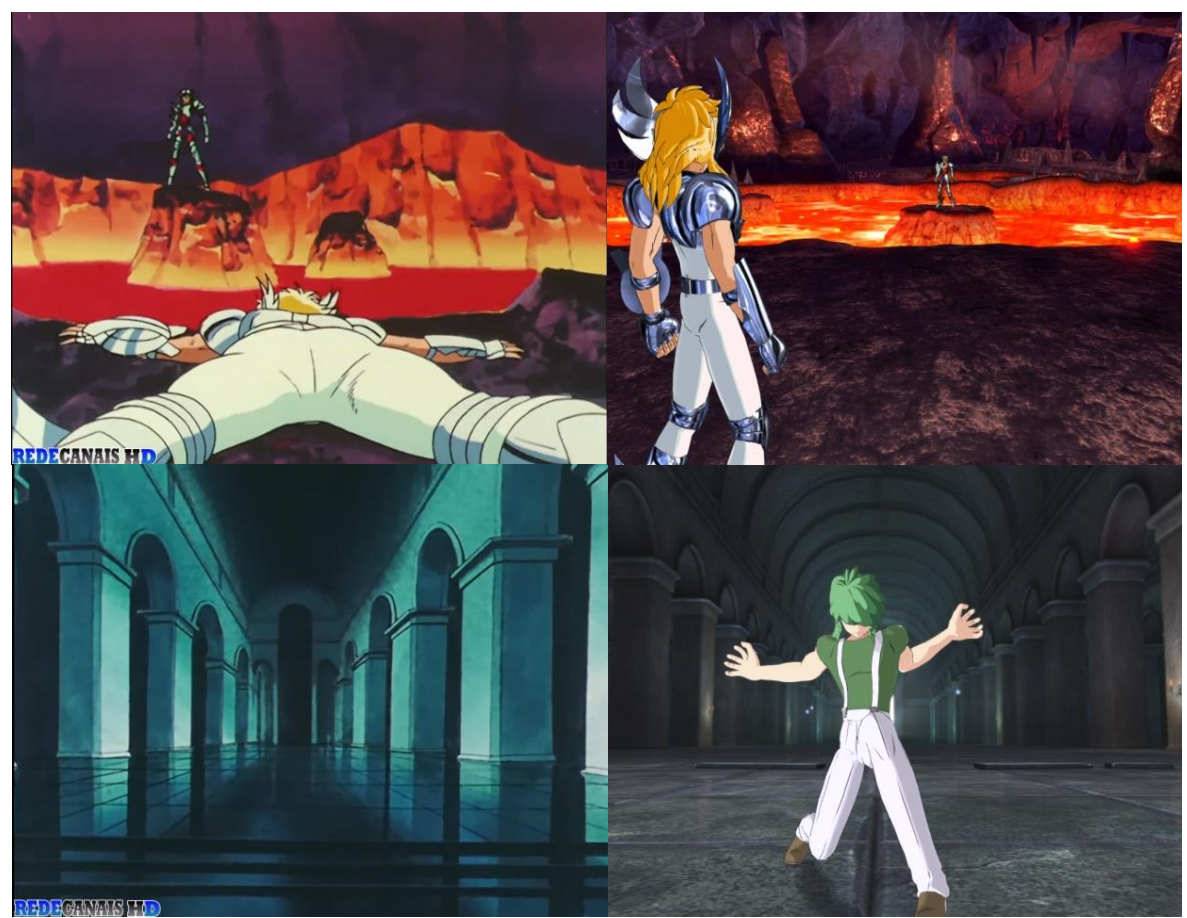

Figura 08: À esquerda a caverna de Hagen e o palácio Valhalla no anime, à direita os mesmos no espaço do jogo Os Cavaleiros do Zodíaco: Alma dos Soldados.

Fonte: Elaborado pelo autor (2018).

Já o palácio de Valhalla, abriga um ar mais sombrio e tenebroso. Trata-se de um cenário com luminosidade reduzia, com largas vigas retangulares e aparentemente maciças, conectadas por vãos arredondados na parte superior e abóbodas no teto (estrutura circular em arcos) ${ }^{15}$. O piso novamente expõe um padrão retangular. O jogo não deixou de lado nenhum desses detalhes e os retratou com considerável capricho.

Mergulhando até o fundo dos oceanos, chegamos ao templo marino destinado ao Deus grego dos mares. Na espacialidade do jogo, o corredor que conecta o pilar principal (local da prisão de Athena) ao Santuário de Poseidon (local de repouso do Deus) ganha destaque em razão da riqueza de detalhes.

Inicialmente, é o próprio pilar principal (tanto no anime quanto no jogo) que chama atenção pela majestade ao fundo da paisagem. O princípio de grandeza material da arquitetura romana é clara referência nesse objeto. Além da força, também o imperativo de utilidade aos equipamentos urbanos é contemplada nessa porção do espaço do jogo, haja visto ser esse o espaço que aprisiona o inimigo (a Deusa Atena).

\footnotetext{
${ }^{15}$ Parece haver nítida inspiração da arte românica presente nos séculos XI, XII e XIII da idade média europeia.
} 
Ainda no pilar principal, na sua base, há diversos corais com coloração rosada que o margeiam, o que reforça a ideia de submersão no oceano. É possível observar também que, em ambos veículos (anime e jogo), o céu do templo corresponde ao fundo do mar.

Posteriormente, são as pilastras laterais, em arquitetura greco-romana, que ganham proeminência no cenário. Há cerca de uma centena dessas pilastras enfileiradas horizontalmente, todas no estilo grego dórico e com pequenas janelas em formato de semicírculos anexas logo acima. Em alguns pontos específicos das laterais, nota-se a presença de duas pequenas chaminés que, isoladas no topo, saltam imediatamente aos olhos. O ideal arquitetônico grego de proporções matemáticas precisas e simetria, ambas como buscas da perfeição, se faz presente na paisagem.

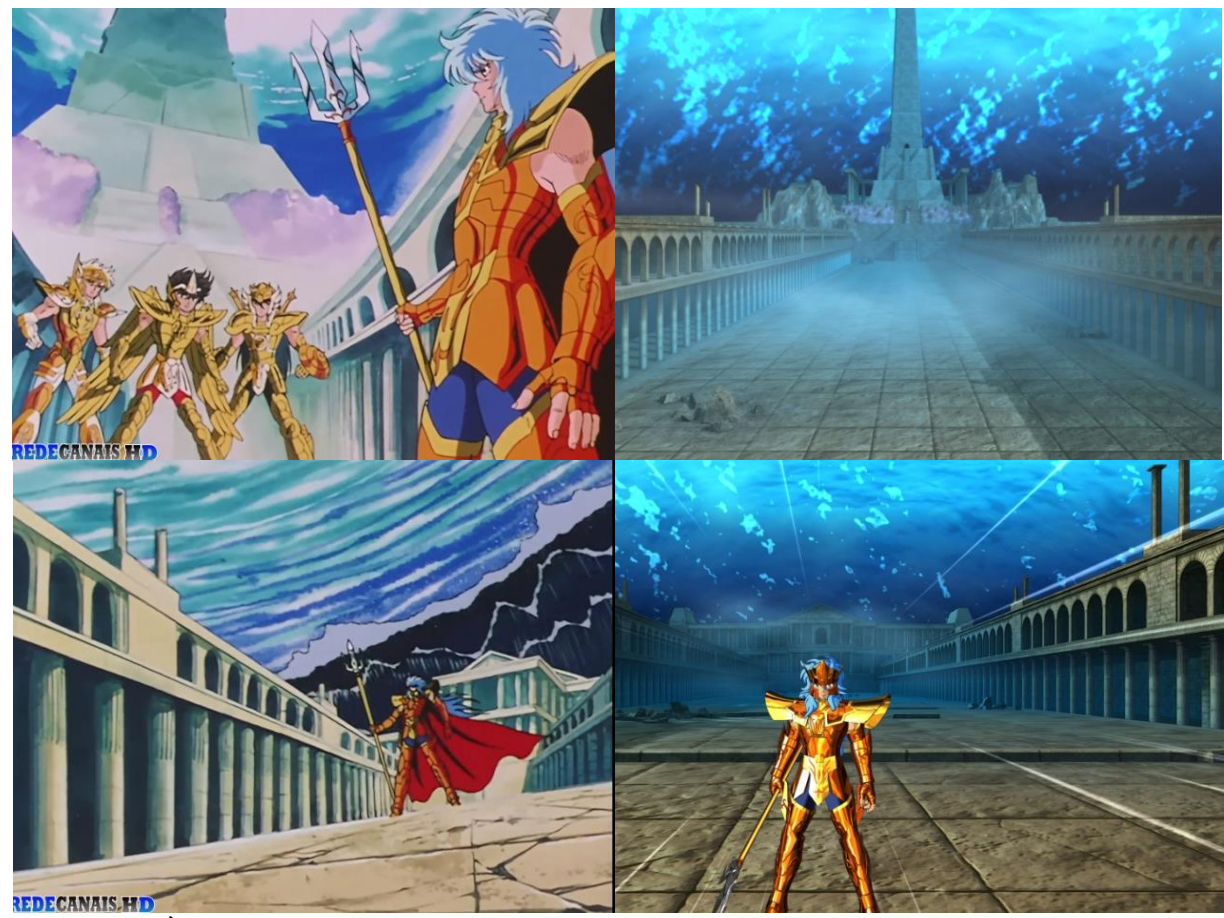

Figura 09: À esquerda o templo de poseidon no anime e à direita o templo no espaço do jogo Os Cavaleiros do Zodíaco: Alma dos Soldados

Fonte: Elaborado pelo autor (2018).

Além dos elementos espaciais já abordados, nas duas imagens inferiores da figura 09 verificamos o Santuário de Poseidon (seu local de repouso) situado ao fundo da paisagem, logo atrás do seu imperador. O Santuário se localiza no extremo oposto do pilar principal. Por fim, o piso exposto, mais uma vez, é retangular, mas diferente do 
palácio de Valhalla. verifica-se considerável desgaste, com a presença de algumas lascas e fendas.

O último espaço do jogo relacionado foi o salão de Giudeca, local onde a alma do Deus grego Hades descansa. É possível notar no anime (em perspectiva oblíqua) o trono do imperador do submundo na parte mais alta do salão. O trono está separado da parte mais baixa por conta de dois lances de degraus. Nas costas do trono há uma parede de cortina e à sua frente, além das escadas, dois pilares e duas estátuas de dragões (extremidades direita e esquerda).

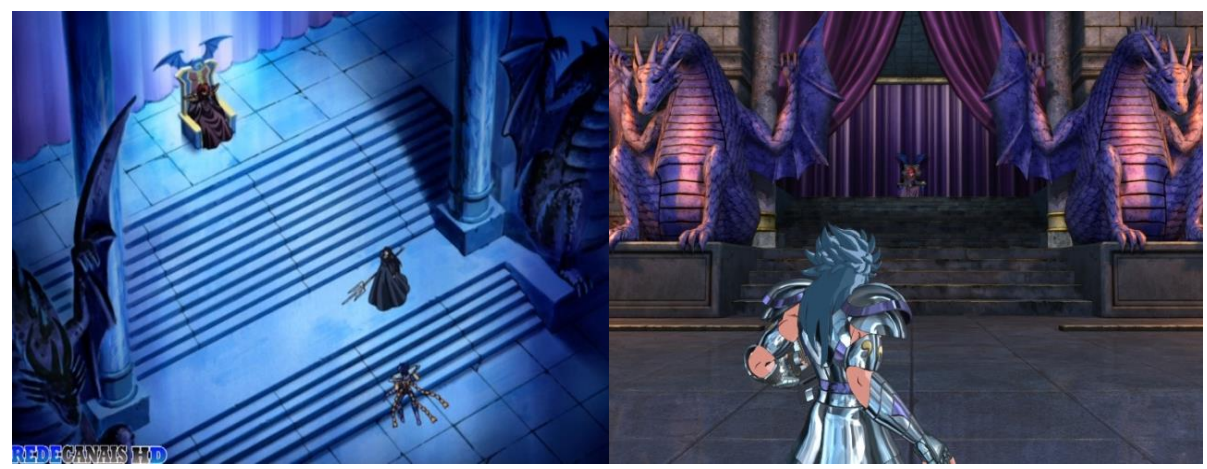

Figura 10: À esquerda o salão da Giudeca no anime e à direita no espaço do jogo $O s$ Cavaleiros do Zodíaco: Alma dos Soldados

Fonte: Elaborado pelo autor.

O espaço do jogo reconstrói cada uma das particularidades mencionadas. A partir de uma perspectiva horizontal (que se pode conferir na imagem à direita da figura 10) a visão pode alcançar as estatuas, os degraus, os pilares, o trono de Hades e o desenho das cortinas ao fundo. É novamente destacável o padrão retangular do piso.

\section{Os Cavaleiros do Zodíaco: Batalha do Santuário}

Diferente do jogo anterior, em Os Cavaleiros do Zodíaco: Batalha do Santuário apenas a primeira temporada do anime é contemplada. Nesse caso, as dose casas zodiacais e o salão do mestre são o palco central da aventura. Mas o grande diferencial desse segundo jogo se dá pela adição de novos espaços a serem explorados dentro do Santuário de Atena.

Em oposição ao outro jogo, as escadarias que ligam as doze casas zodiacais são aqui espaços jogáveis dentro da trama e o jogador precisar avançar por esses caminhos. Em outras palavras, em Os Cavaleiros do Zodíaco: Batalha do Santuário é obrigatório acessar e explorar espaços que o game anterior nem mesmo abarca, entre eles, o épico "caminho das rosas", trata-se do último trajeto da primeira saga, localizado entre a casa zodiacal de Peixes e a sala do grande Mestre. 
Há diferença também em relação ao anime, onde os trajetos entre as casas são dominados apenas por escadarias, como mostra a primeira imagem da figura 11 . No jogo, porém, os próprios degraus (e mais alguns patamares adicionados) configuram-se como espaços de combate (figura 05), onde adversários mais fracos tentam impedir o avanço do jogador.

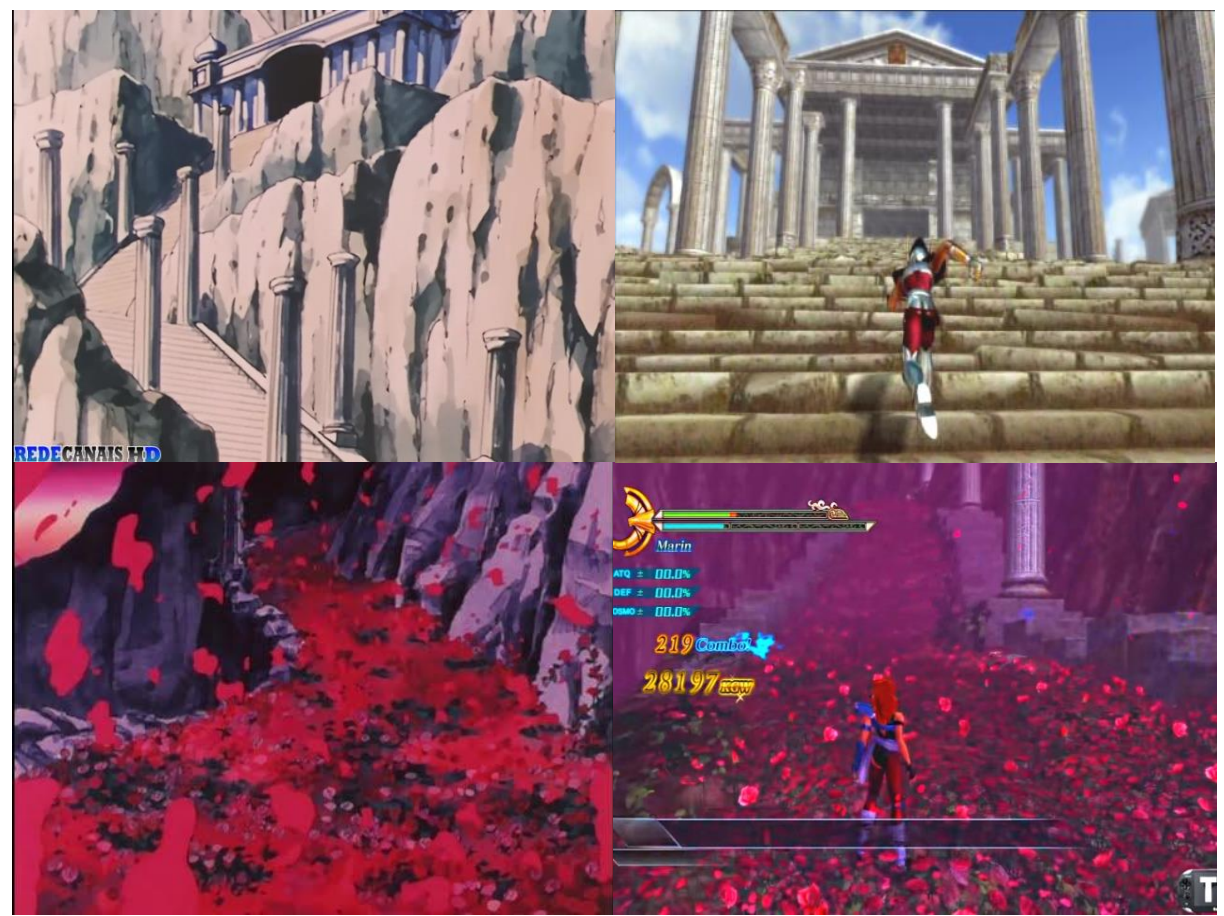

Figura 11: À esquerda acima, a escadaria do santuário, e abaixo, o caminho das rosas, ambos no anime. À direita, os mesmos trajetos no espaço do jogo Os Cavaleiros do Zodíaco: Batalha do Santuário

Fonte: Elaborado pelo autor (2018).

Vale ressaltar que essa incorporação de ações (inexistentes no anime) que o jogo promove, em alguns espaços, é muito importante para compor a experiência do gênero de jogo, afinal, subir escadarias sem qualquer confronto ou desafio, poderia esvaziar a dinâmica aguerrida que um videogame de luta demanda, tornando-o tedioso. Isso revela que algumas adaptações realizadas nos espaços evocativos dos videogames, exigem requalificar e até refuncionalizar alguns espaços.

A paisagem desses percursos é toda inspirada na arquitetura clássica grecoromana, são degraus montados por paralelepípedos encaixados, delimitados lateralmente por colunas gregas e fincados em costões rochosos. A exceção fica a cargo do último dos caminhos, posterior à casa de Peixes. Esse trajeto final é o que mais destoa dos demais, 
pois é todo coberto por rosas que contêm veneno em seu aroma (figura 11). O jogo reproduz fielmente o artifício das rosas e, assim como no anime, elas causam danos ao jogador, uma alusão ao veneno que transportam em suas pétalas.

\section{Conclusão}

O presente estudo buscou analisar os jogos Os Cavaleiros do Zodíaco: Alma dos Soldados (PC) e Os Cavaleiros do Zodíaco: Batalha do Santuário (PS3) à luz da classificação dos espaço evocativos proposta por Jenkins (2004). Observou-se que os jogos promovem uma ambiência inspirada na obra original. Os elementos espaciais do anime foram infundidos nos espaços dos jogos visando atender as expectativas semióticas dos jogadores e, com isso, elevar as suas experiências com esses espaços a um nível superior.

Nesse sentido, os jogos se configuram, efetivamente, como autênticos espaços evocativos, pois deram conta de evocar a atmosfera da história e da espacialidade original do anime, com um elemento adicional por serem jogos eletrônicos: oferecem a possibilidade de interação e navegação (papel ativo do usuário) pelos espaços antes conhecidos apenas (de forma passiva) no anime. Se a intenção dos desenvolvedores foi fazer o jogador se sentir, verdadeiramente, dentro desses espaços fantasiados, oriundos de outra mídia, parece ter tido êxito.

Além dos espaços evocativos dos jogos amplificarem o senso de imersão dos jogadores no universo particular da obra Os Cavaleiros do Zodíaco, eles também conseguiram comunicar novas perspectivas da história e da espacialidade, e isso foi observável a partir de dois mecanismos pontuais.

De um lado, foi possível notar que, para além do anime, pequenas informações da história foram adicionadas nos jogos através de diálogos entre personagens em situações novas, que não existem na trama original. São perspectivas da história contadas a partir do ponto de vista de algum personagem específico, abordando suas opiniões e como ele percebe a sucessão dos eventos da trama. É possível observar esse mecanismo, como exemplo, em Os Cavaleiros do Zodíaco: Batalha do Santuário (no modo de jogo "Saga de Aiolos"), no qual o cavaleiro de ouro de Sagitário dialoga com os cavaleiros de ouro de Peixes e Aquário, expondo sua visão dos fatos e adicionando dados inéditos.

Do outro lado, percebeu-se que os espaços dos jogos não são representações fechadas dos espaços do anime. Embora evocativos, há uma série de elementos que foram adicionados nas paisagens e que são exclusivos dos jogos, tais como os tronos de Escorpião e Leão nas suas respectivas casas zodiacais em Os Cavaleiros do Zodíaco: Alma dos Soldados; e também os patamares de combate entre as escadarias do Santuário de Atena em Os Cavaleiros do Zodíaco: Batalha do Santuário. Esses elementos espaciais exclusivos dos jogos, juntamente com os diálogos inéditos, participam na ampliação do universo da obra. 
Com base nos elementos observados, é possível concluir que diferente de outros jogos onde a paisagem pode informar a dificuldade do jogo ou sugerir as ações a serem executadas pelo jogador, nos jogos aqui analisados, ela desempenhou papéis bem específicos: contribuir para uma maior imersão do jogador no universo da obra e informar pequenos elementos espaciais adicionais.

Por fim, o presente trabalho reitera a capacidade que as narrativas transmidiáticas têm de expandir nossa experiência com as obras e nos dar uma compreensão mais rica dos seus mundos. Nos videogames, isso se dá a partir da modelagem dos espaços digitais, das suas paisagens e do potencial ativo que a jogabilidade oferece ao jogador. Para a Geografia, há um enorme potencial de enriquecimento do seu campo analítico, e de abordagem, ao interpretar as diversas espacialidades expostas por essas mídias.

\section{Referências bibliográficas}

AARSETH, E. Allegories of Space: The Question of Spatiality in Computer Games. In ESKELINEN, M.; KOSKIMAA, R. (eds.) Cybertext Yearbook. 2000, University of Jyväskylä, 2000.

AARSETH, E. Cibertext: perspectives on Ergotic Literature. The Johns Hopkins University Press, Baltimore, 1997.

ASH, J. e GALLACHER, L. The cultural geographies of videogame. Geography Compass, 5/6, 2011.

ASH, J. Emerging spatialities of the screen: video games and the reconfiguration of spatial awareness". Environment and Planning A 41(9), 2009, p. 2105 - 2124.

COLOM, R. Structural changes after videogame practice related to a brain network associated with intelligence. Intelligence, vol:40, fasc:5. 2012.

DRUMMOND, W. Geografia em jogo: algumas possibilidades de abordagem dos videogames na Geografia. In: Ateliê Geográfico - Goiânia-GO, v. 10, n. 1, p. 140-159, abr./2016

DRUMMOND, W. Geografia nos videogames: representação e discurso espacial no game simulador SimCity 4. Dissertação de Mestrado apresentada no Programa de Pós Graduação em Geografia da Universidade Federal do Rio de Janeiro - PPGG, 2014. Disponível em:

http://www.academia.edu/6912057/Representa\%C3\%A7\%C3\%A3o_espacial_nos_vide ogames_explorando_o_caso_Simcity_4

GOMES, P. Cenários para a geografia: sobre a espacialidade das imagens e suas significações. In: ROSENTAL, Z. e CORRÊA, R. L. (org.) Espaço e Cultura: pluralidade temática, Rio de Janeiro: EdUERJ, 2008. 
GOMES, R. Narratologia \& Ludologia: um novo round. VIII Brazilian Symposium on Games and Digital Entertainment. Rio de Janeiro, RJ - Brazil, 2009.

JENKINS, H. Game Design as Narrative Architecture. First Person: New Media as Story, Performance, and Game. Eds. Noah Wardrip-Fruin and Pat Harrigan. Cambridge: MIT Press, 2004.

LINDLEY, C. Game taxonomies: a high level framework for game analysis and design. Gamasutra, 2003, p. 1. Disponível em: http://www.gamasutra.com/view/feature/2796/game_taxonomies_a_high_level_.php

MCGONIGAL, J. A realidade em jogo. Rio de Janeiro: BestSeller, 2012

MURRAY, J. Hamlet on the Holodeck The Future of Narrative in Cyberspace. The free press, Nova York, 1998.

MUSSA, I. História espacial e os mecanismos de interação nos jogos eletrônicos. In: X SBGames - Salvador - BA, November, 2011.

PEARCE, C. Spatial Literacy: Reading (and Writing) Game Space, 2005. Disponível em:

https://pdfs.semanticscholar.org/e538/9481c4375d5c60c6577a2cd5333b59a942fc.pdf

SHAW, I. e WARF, B. Worlds of affect: virtual geographies of videogames. Environment and planning A 41. 2009, p. 1332-1343.

VANDELLÓS, A. Videojuegos como dispositivos culturales: las competências espaciales en educación. Comunicar, $\mathrm{n}^{\circ} 34$, v. XVII, Revista Científica de Educomunicación; ISSN: 1134-3478; 2010.

\footnotetext{
Washington Drummond da Silva

Geógrafo e Mestre em Geografia pelo programa de pós-graduação do departamento de Geografia da Universidade Federal do Rio de Janeiro. Atualmente é professor substituto de Geografia Humana (Bacharelado e Licenciatura) da UFRJ e professor efetivo da rede estadual de educação do estado do Rio de Janeiro.

Bloco A - Av. Athos da Silveira Ramos, 274 - Cidade Universitária, Rio de Janeiro - RJ - CEP 21941-901.

mr.slash2@yahoo.com.br
}

Recebido para publicação em setembro de 2018

Aprovado para publicação em janeiro de 2019 